\title{
Mortality associated with extremity injuries compared with other types of trauma
}

\author{
This article was published in the following Dove Press journal: \\ International Journal of General Medicine \\ 4 April 20II \\ Number of times this article has been viewed
}

\author{
José Eduardo Arantes \\ Sanches' \\ José Maria Pereira de \\ Godoy ${ }^{3}$ \\ André Luciano Baitello² \\ Alceu Gomes Chueire' \\ 'Departments of Orthopedic and \\ Traumatology, ${ }^{2}$ Trauma, ${ }^{3}$ Cardiology \\ and Cardiovascular Surgery, \\ Faculty of Medicine, São Jose \\ do Rio Preto, Brazil
}

Background: The aim of this study was to evaluate one-month hospital mortality in victims with injuries of the extremities.

Methods: All accident victims admitted to the Hospital de Base in São José do Rio Preto, Brazil, during the period from July 2004 to June 2005, were evaluated in an observational study. Patients were classified using the Abbreviated Injury Scale (AIS). Patients with severe injuries of the extremities (AIS 3-4) were compared with those without injuries or with minor extremity injuries (AIS 0-2).

Results: A total of 3489 accident victims were evaluated; 3244 (92.98\%) did not suffer injuries or had minor injuries of the extremities (AIS 0-2) and 245 (7.02\%) had severe injuries (AIS 3-4). Of the 245 patients with AIS 3-4 extremity injuries, $13(5.31 \%)$ patients died, and of those without severe injuries to the extremities, 34 (1.05\%) died (Fisher's Exact test $P=0.0000$, relative risk 5.063, 95\% confidence interval [CI]: 2.707-9.467).

Conclusion: Patients with injuries of the extremities are at greater risk of death than accident victims with other types of trauma.

Keywords: trauma, extremities, mortality, Brazil

\section{Introduction}

The treatment of patients with multiple trauma requires a different approach to that of patients with regular trauma because they are threatened not only by the injuries themselves, but also by the metabolic disruptions that follow. ${ }^{1}$ Delay in surgery, blunt trauma, extensive soft tissue damage, and combined orthopedic and vascular injuries have been associated with an increased risk of amputation, while associated nerve and bone injuries with extensive soft tissue damage are risk factors for a poor outcome. ${ }^{2}$

Acute renal failure is the main cause of death in patients with war wounds and trauma of the extremities. It would be helpful to minimize mortality in these patients by managing shock in a timely manner and taking the decision to amputate appropriately and promptly. ${ }^{3}$ Severe head injury is known to be a major determinant of mortality in patients with multiple injuries, but other injuries also contribute to the clinical outcome. ${ }^{4,5}$

Different mechanisms of injury, such as motor vehicle crashes, falls, or pedestrians being struck by a motor vehicle, impart varying degrees of force and energy transfer that may impact outcomes; this was found to predict mortality and functional impairment independently at hospital discharge. ${ }^{6}$ Acute lower extremity compartment syndrome is a devastating complication that often presents silently in critically injured patients. ${ }^{7}$ Patients who underwent delayed fasciotomy had twice the rate of major amputation 
Table I Degree of injury to the extremity and mortality rate

\begin{tabular}{llll}
\hline Trauma score & Survivors & Died & Total \\
\hline AIS 0-2 & $3210(98.95 \%)$ & $34(1.05 \%)$ & $3244(92.98 \%)$ \\
AIS 3-4 & $232(94.69 \%)$ & $13(5.31 \%)$ & $245(7.02 \%)$ \\
\hline
\end{tabular}

Note: Fisher's Exact test: $P$-value $=0.000012$.

and a three-fold higher mortality rate. ${ }^{8}$ The aim of this study was to evaluate if injuries of the extremities are associated with a higher one-month mortality rate than other types of associated trauma.

\section{Methods}

This prospective, observational, cohort study was carried out in the Regional Emergency Center of Hospital de Base after prior approval by the Ethics Research Committee of the São José do Rio Preto Medical School. The emergency department follows a systematic pathway to provide initial assistance to accident victims using the ATLS $^{\circledR}$ (Advanced Trauma Life Support) protocol. All live accident victims treated in the emergency department from July 2004 to June 2005 were included. Patients who were dead on arrival and not submitted to any type of inhospital resuscitation procedure were not included in the study.

Accident victims were allocated to two groups, ie, those with severe injuries to the extremities or pelvis (Abbreviated Injury Scale [AIS] 3-4) and those without injuries or with minor injuries to the extremities (AIS 0-2). The Fisher's Exact test and relative risk were used for statistical analysis, and an alpha error of $5 \%(P \leq 0.05)$ was considered statistically significant.

\section{Results}

A total of 3489 patients were evaluated in this study; 3244 $(92.98 \%)$ did not have severe trauma of the extremities
(AIS 0-2), 34 (1.05\%) of whom died. Severe injuries of the extremities (AIS 3-4) occurred in 245 (7.02\%) of the patients, with 13 (5.31\%) dying (Fisher's Exact test: $P=0.001$, relative risk 5.063, 95\% confidence interval [CI]: 2.707-9.467, Table 1). Table 2 shows the age, type of injury sustained, and time until death after trauma for the patients who died. Of the 245 patients with AIS 3-4, 71 (28.98\%) were women and $174(71.02 \%)$ were men, with the mean age of the men being $40.1 \pm 20.5$ years and of the women $60.2 \pm 23.6$ years.

\section{Discussion}

This study assessed whether severe injuries of the extremities affect the overall mortality rate in accident victims. The death rate was found to be higher for patients with AIS 3-4 than in those without injuries or with minor injuries to the limbs. Thus, these data serve as a warning in respect to increased risk of death in orthopedic patients compared with general trauma patients. When the severity of specific injuries in accident victims is reported in the literature, head trauma is cited as one of the main causes of death.${ }^{5,6}$ However, there are few data in the literature about the association between death and injuries to the extremities. One study reported that the mortality rate in accident victims with extremity injuries was higher in pedestrians struck by motor vehicles $(20 \%)$, and for those with head injuries, it was higher for motor cycle crash victims $(16 \%){ }^{6}$

The first phase of management for these patients aims to control bleeding, by surgical intervention if necessary, and to prevent further wound contamination. The second phase consists of resuscitation in the intensive care unit, and the third phase aims at definitive repair of the injuries sustained. ${ }^{9}$ Pelvic injuries represent a thorny and stubborn therapeutic challenge. Rapid diagnosis and effective treatment ("damage control") of these injuries play a key role in

Table 2 Age, types of trauma, and time of death after the accident

\begin{tabular}{lllll}
\hline Patient & Age (years) & Extremity injured & Concomitant injuries & Time to death (days) \\
\hline 1 & 35 & Arm & Pneumothorax & 2 \\
2 & 44 & Multiple injuries & Cerebral edema & 3 \\
3 & 89 & Arm & Pneumonia & II \\
4 & 43 & Multiple injuries & Sepsis & 8 \\
5 & 28 & Leg & Cerebral edema & 2 \\
6 & 20 & Leg & Abdominal/kidney & 8 \\
7 & 44 & Leg & Cerebral edema & 2 \\
8 & 49 & Leg & Respiratory failure & 6 \\
9 & 55 & Leg & Hemithorax & 2 \\
10 & 58 & Leg & Cerebral edema & 8 \\
11 & 21 & Leg & Cerebral edema & 6 \\
12 & 23 & Leg & Abdominal/liver & 2 \\
13 & 22 & Leg & Abdominal/cava vein & 3 \\
\hline
\end{tabular}


the patient's survival, inasmuch as the mortality of multiply injured patients with pelvic ring disruption remains high $(20 \%-35 \%) .^{10}$

The preclinical management of patients with multiple trauma influences the prognosis regarding mortality and morbidity. Diagnostic overview, protection of vital functions in the special circumstance of shock, immobilization of the spine, and treatment of isolated injuries are an essential part of preclinical management. ${ }^{11}$ The type of trauma is known to influence the mortality rate. ${ }^{12}$

In this study, all the patients received specialized prehospital assistance, and were treated in a regional trauma reference center. In spite of all the care given at the scene of the accident through to discharge from hospital, trauma of the extremities was a significant cause of death.

\section{Conclusion}

Accident victims with injuries of the extremities are at higher risk for death than those with other types of trauma.

\section{Disclosure}

The author reports no conflict of interest in this work.

\section{References}

1. Andeweg CS, Vingerhoedt NM, van Vugt AB, Haerkens MH. Damage control surgery in polytraumatized patients. Ned Tijdschr Geneeskd. 2006;150(27):1503-1507.
2. Heis HA, Bani-Hani KE, Elheis MA. Overview of extremity arterial trauma in Jordan. Int Angiol. 2008;27(6):522-528.

3. Cheng CZ, Zhao DH, Li QY, Qu HY, Chen BC, Lin ZD. The causes of death and risk factors in patients of war wound and trauma of extremities by logistic regression model. Zhonghua Yi Xue Za Zhi. 2008;88(47):3325-3328. Chinese.

4. Lefering R, Paffrath T, Linker R, Bouillon B, Neugebauer EA; German Society for Trauma Surgery. Head injury and outcome - what influence do concomitant injuries have? J Trauma. 2008;65(5):1036-1043.

5. Colantonio A, Escobar MD, Chipman M, et al. Predictors of postacute mortality following traumatic brain injury in a seriously injured population. J Trauma. 2008;64(4):876-882.

6. Haider AH, Chang DC, Haut ER, Cornwell EE 3rd, Efron DT. Mechanism of injury predicts patient mortality and impairment after blunt trauma. J Surg Res. 2009;153(1):138-142.

7. Kosir R, Moore FA, Selby JH, et al. Acute lower extremity compartment syndrome (ALECS) screening protocol in critically ill trauma patients. J Trauma. 2007;63(2):268-275.

8. Ritenour AE, Dorlac WC, Fang R, et al. Complications after fasciotomy revision and delayed compartment release in combat patients. JTrauma. 2008;64(2 Suppl):S153-S161.

9. Andeweg CS, Vingerhoedt NM, van Vugt AB, Haerkens MH. Damage control surgery in polytraumatized patients. Ned Tijdschr Geneeskd. 2006;150(27):1503-1507.

10. John T, Ertel W. Pelvic injuries in the polytraumatized patient. Orthopade. 2005;34(9):917-930.

11. Döhnert J, Auerbach B, Wyrwich W, Heyde CE. The preclinical care of polytraumatized patients. Orthopade. 2005;34(9):837-851.

12. Cury F, Baitello AL, Echeverria RF, Espada PC, Pereira de Godoy JM. Rates of thoracic trauma and mortality due to accidents in Brazil. Ann Thorac Med. 2009;4(1):25-26.
International Journal of General Medicine

\section{Publish your work in this journal}

The International Journal of General Medicine is an international, peer-reviewed open-access journal that focuses on general and internal medicine, pathogenesis, epidemiology, diagnosis, monitoring and treatment protocols. The journal is characterized by the rapid reporting of reviews, original research and clinical studies across all disease areas.

\section{Dovepress}

A key focus is the elucidation of disease processes and management protocols resulting in improved outcomes for the patient. The manuscript management system is completely online and includes a very quick and fair peer-review system. Visit http://www.dovepress.com/ testimonials.php to read real quotes from published authors. 